\title{
POR UMA REGIONALIZAÇÃO NA ESCALA DO MERCOSUL: DESAFIOS PARA A CONSTRUÇÃO DE UM PARADIGMA PARA A GEOGRAFIA SUL-AMERICANA
}

\author{
A proposal of regionalization on the scale of MERCOSUR: \\ challenges for the construction of a paradigm for South American geography
}

Prof $^{a}$ Dr. Claudio A. G. Egler

Programa de Pós-Graduação em Geografia UFRJ Instituto de Geociências, CEP: 21945-570 - Rio de Janeiro, RJ - Brasil Tel/Fax: (+55 21) 22707773 / 22707773 - egler@ufrj.br

\section{${ }_{a} a \boldsymbol{a} a a$}

\begin{abstract}
Resumo
A construção de um novo paradigma de análise geográfica para a compreensão da dinâmica espacial na América do Sul é um desafio para os geógrafos brasileiros. Uma das vias possíveis para avançar nessa direção é o emprego do instrumental da geoeconomia, principalmente no que diz respeito à aplicação da análise institucional na leitura do território. O presente artigo se propõe a perseguir nessa direção através de uma regionalização preliminar na escala do Mercosul.
\end{abstract}

Palavras Chave: Regionalização, MERCOSUL, América do Sul

\begin{abstract}
The construction of a new paradigm of geographical analysis to understanding the spatial dynamics in South America is a challenge for the Brazilian geographers. One of the possible ways forward in this direction is the use of instruments of geoeconomics, especially as regards the application of institutional analysis in the reading of the territory. This article intends to pursue in this direction through a preliminary regionalization at the scale of Mercosul.
\end{abstract}

Key Word: Regionhalization, MERCOSUR, South American.

\section{Resumen}

La construcción de un nuevo paradigma de análisis geográfico para la comprensión de la dinámica espacial en América del Sur es un desafío para los geógrafos brasileños. Una de las posibles formas de avanzar en esta dirección es el uso de instrumentos de la geoeconomía, especialmente en cuanto a la aplicación del análisis institucional en la lectura del territorio. Este artículo tiene la intención de seguir en esta dirección a través de una propuesta preliminar de regionalización en la escala del Mercosur..

Mots-Clés Regionalisation, MERCOSUL, Amerique du Sud.

\section{${ }_{a} a \boldsymbol{a}_{a} a$}




\section{INTRODUÇÃO}

O Mercado Comum do Sul (MERCOSUL), formado pelo Brasil, Argentina, Uruguai e Paraguai, foi instituído através do Tratado de Assunção em 1991. Desde então, pouco se avançou quanto à profundidade do efetivo processo de integração regional, que ainda está muito longe da União Aduaneira prevista para 1994, porém ampliou-se bastante a sua área de abrangência, com a entrada de vários membros-associados, como o Chile (1996), Bolívia (1997), Peru (2003) e Venezuela (2004), culminando, em dezembro de 2004, com a proposta de criação de uma Comunidade Sul-Americana de Nações.

O processo de integração sul-americano tem apresentado avanços importantes a partir da década de 1990, apesar das pressões geopolíticas e geoeconômicas internas e externas contra a sua efetivação, entretanto também recuos podem ser encontrados - principalmente nas freqüentes disputas comerciais entre os dois principais parceiros do bloco: Brasil e Argentina. Tais contradições estão presentes tanto nos acordos bilaterais de alguns países sul-americanos com parceiros de outros blocos econômicos, o que tem enfraquecido o multilateralismo continental, como na tentativa norte-americana de impor o "fast track" como mecanismo de implantação acelerada da Área de Livre Comércio das Américas (ALCA), inviabilizando o cronograma de ajustes necessários para a consolidação do Mercosul. .

Por outro lado, a nova realidade resultante do lançamento da Comunidade Sul-Americana de Nações, atual União de Nações Sul-americanas (UNASUL), bem como do aguçamento dos conflitos regionais em diversas partes do continente em conseqüência da emergência de novos atores no cenário geoeconômico, como é o exemplo das comunidades indígenas na Bolívia e Equador, que acabam por defrontar-se com fronteiras de expansão de empresas de origem brasileira, como a AMBEV e a Petrobrás, acabam por abrir novas linhas de conflitos entre agentes locais, nacionais e globais (EGLER E PIRES DO RIO; 2004).

Nesse contexto, a conjunção das tendências de integração-fragmentação está redefinindo os marcos institucionais que regulam os espaços sub-nacionais (SIROËN; 2004), reafirmando a importância das regiões como territórios de negociação (SILVEIRA; 2005), capazes de reduzir os custos de transação (NORTH; 2001) inerentes ao processo de integração supranacional.

Do ponto de vista político, o movimento social na Bolívia reproduz a idéia da multidão, onde uma miríade de movimentos sociais, muitos deles territorializados em diversas partes do país, sejam de origem mineira, agricultores, pequenos comerciantes informais, que se unem em torno da bandeira política da mudança e em busca da nacionalização de suas reservas de petróleo e gás natural. Esses movimentos, embora tenham potencial transformador, também expressam propostas conservadoras, tanto do ponto de vista político, como também social.

Tanto Bolívia, como o Equador, que são países de forte presença indígena. Essa população permaneceu a margem dos direitos elementares da cidadania do estado-nação moderno, do qual participou como 'partner' secundário e mesmo marginal. Na verdade, jamais formaram uma nação, mas integravam diversas delas. Assim, pode-se entender que foram estrangeiros em seu próprio país, já que formavam um conjunto de nações que foram relegados aos segundo plano pelo Estado, que no máximo os tutelou.

É nesse quadro, que se pode colocar a proposta indígena de um Estado multinacional, isto é que seja capaz de integrar as diversas nacionalidades presentes no território. É nesse contexto que se pode perguntar qual o sentido contemporâneo de fronteiras e como são tratadas para expressar esse novo cenário de fragmentação dos Estados-Nacionais e Integração supranacional, principalmente promovido pelas redes transnacionais.

O papel das relações entre estado e mercado na definição do marco institucional dentro do qual operam as organizações, depende não apenas de fatores econômicos, mas também, e principalmente, históricos e culturais. O papel de guardião dos lugares, atribuído institucionalmente ao estado, não é suficiente para garantir o controle efetivo sobre o território, que é compartilhado com as empresas que operam as redes logísticas que o atravessam. Essas, por sua vez, embora desejassem a volatilização 
total das redes físicas, continuam prisioneiras do território e sujeitas a capacidade de mobilização social de seus habitantes.

No contexto do MERCOSUL, as disparidades regionais internas ainda representam um formidável obstáculo a ser transposto pelas economias nacionais, porém tal obstáculo só pode ser enfrentado a partir de um novo marco institucional que conceda às regiões um papel central diante dos objetivos estratégicos da integração sul-americana.

Do ponto de vista conceitual, a linha teórica que norteia a pesquisa é a aplicação da análise institucional à leitura do território (AMIN; 1998), resgatando o conceito de região como resultante de arranjos institucionais, onde as comunidades territoriais desempenham papel relevante (STORPER; 1997). Especial atenção será dada à rede de cidades na configuração da estrutura regional sul-americana, considerando o papel desempenhado pelas relações interurbanas na organização espacial em escala global (TAYLOR; 2003). Concorda-se, nesse aspecto, com a argumentação de Cumbers, Mackinnon e McMaster (2003) sobre os aportes institucionalistas que constituem uma abordagem integrada a uma perspectiva dinâmica que não priorizam uma escala específica, mas ao contrário, consideram as regiões produzidas e reproduzidas pela ação de organizações e instituições.

\section{A GEOECONOMIA COMO PARADIGMA}

Em português, no senso comum é usual encontrar geopolítica e geoeconomia como formas abreviadas de geografia política e geografia econômica. Isto ocorre tanto nos dicionários, como em livros bastante difundidos, como é o caso de Geopolítica do Brasil de Golbery do Couto e Silva (COUTO E SILVA, 1967: 165). Uma das primeiras regionalizações do Brasil, realizada em 1939 pelo Conselho Técnico de Economia e Finanças definiu cinco "zonas geoeconômicas", que se aproximam bastante às atuais grandes regiões do IBGE e que segundo Guimarães (1941: 366-8) constituía uma das melhores regionalizações econômicas do território nacional.

A crítica ao economicismo e a orientação preferencial para os fatores culturais e comportamentais é uma tendência observada em vários autores no pensamento geográfico brasileiro contemporâneo. Entretanto, o diálogo entre a geografia e a economia está no fundamento da construção do conhecimento nestas duas áreas científicas no Brasil. Autores como Roberto Simonsen, Celso Furtado e Inácio Rangel, que estão nas raízes da construção do pensamento econômico brasileiro jamais negligenciaram a dimensão espacial em suas análises. No caso da geografia, a recíproca é verdadeira, pois Nelson Werneck Sodré, Caio Prado Junior, Manuel Correia de Andrade e Orlando Valverde sempre fundaram suas observações das formas geográficas nos processos econômicos que contribuíram para a sua construção. Em síntese, pelas próprias características do desenvolvimento brasileiro, o diálogo entre geografia e economia está nos alicerces da construção do pensamento social.

Hoje é mais fácil encontrar referências à geoeconomia entre economistas como Pochman (2007), Tavares (1997) e Fiori (2008) isto porque alguns autores do campo da geografia condenam a opção pela geoeconomia como um abandono prematuro da concepção de geografia econômica. Outros apontam para a geoeconomia como a sucessora da geopolítica no período em que os estados nacionais passam atuar como promotores da conquista de mercados em escala global. Neste texto vamos buscar ir além destas visões e mostrar que a convivência entre geografia econômica, geoeconomia e geopolítica é, não apenas perfeitamente possível, como também necessária, para avançar na compreensão das contradições do mundo contemporâneo.

Nos textos originais de Lütgens (1954), um dos fundadores da Escola de Hamburgo em Geografia Econômica a geoeconomia está presente nas análises sobre a distribuição dos fatos e processos econômicos na superfície da Terra. Embora ocupando uma posição secundária na Escola, os princípios geoeconômicos - que ajudavam a explicar o comportamento dos agentes sociais no espaço econômico, como os anéis concêntricos de Thünnen ou as estruturas hexagonais de Christal- 
ler, estão subjacentes em muitas passagens da obra maior dos geógrafos de Hamburgo, que reunia expoentes como Lütgens e Otremba.

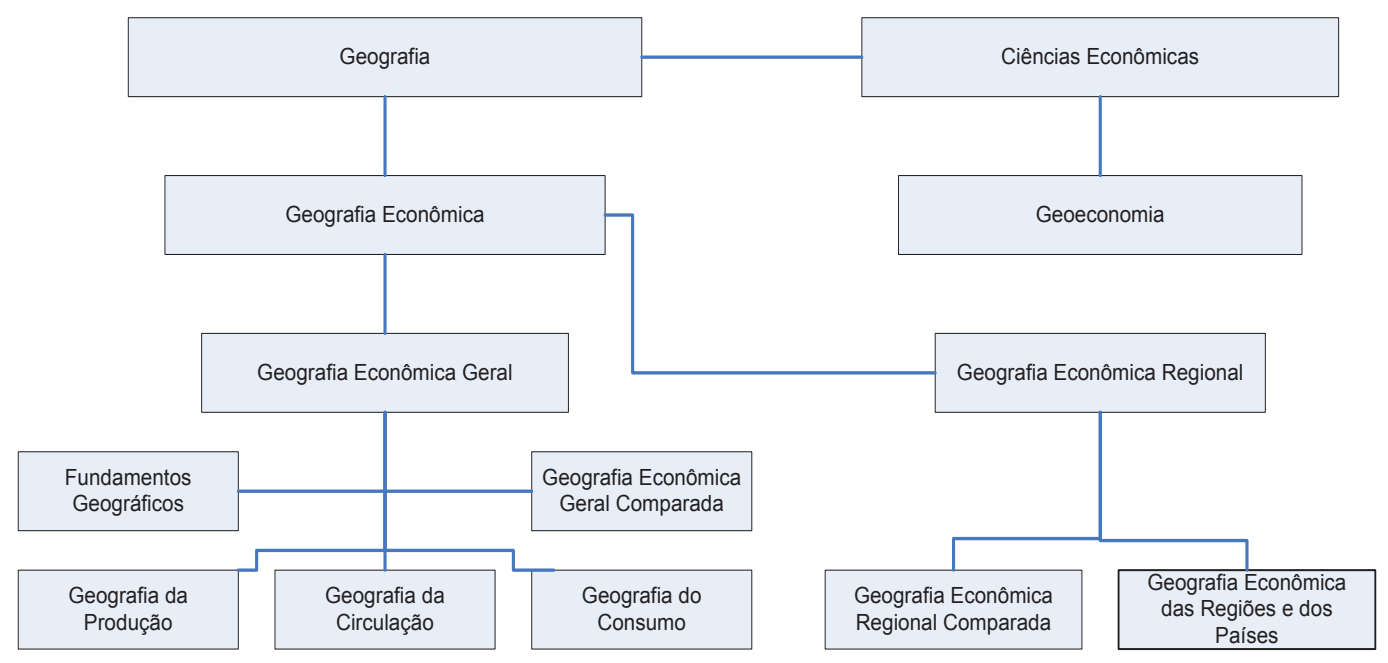

Figura 1 - Esquema Estrutural da Geografia Econômica Segundo Lutgens Fonte: Lütgens, 1954

Se para os geógrafos alemães, a geoeconomia constituía um ramo teórico acessório da geografia econômica, para os norte-americanos possuía um sentido muito mais pragmático e aplicado. Renner (1942) em um manual de geografia humana voltado para a interpretação dos efeitos da difusão do transporte aéreo na circulação mundial, utiliza o termo 'geonomics' para descrever processos que são "geographic in origin but economic in result" (RENNER. 1942: 215). O exemplo citado por esse autor para caracterizar um típico processo geoeconômico diz respeito às mudanças nos fluxos internacionais de pessoas e mercadorias em função da introdução do avião como meio de transporte. Trata-se de uma boa pista para explorar as relações entre geografia econômica e geoeconomia.

O transporte aéreo é uma típica inovação do século XX e sua generalização pode ser considerada como uma peça-chave daquilo que se denomina como o 'encurtamento' das distâncias entre os lugares. O avião não apenas aumentou a velocidade de circulação, como também conferiu relativa autonomia às redes de transporte quanto às condições naturais de seu itinerário. Seja o gerente financeiro de uma multinacional com filiais dispersas em diversos continentes, seja o garimpeiro no interior da Amazônia, ambos dependem da rapidez e da flexibilidade do transporte aéreo.

De certa maneira, Renner (op. cit) ao utilizar o termo geoeconomia para analisar os efeitos do transporte aéreo sobre a circulação mundial foi precursor de uma de suas atribuições mais importantes, isto é, a análise dos fluxos de capitais, mercadorias e pessoas. Foi o avião que iniciou a "separação do espaço dos fluxos do espaço dos lugares" como afirmou Castells (1986) e contribuiu decisivamente para a "compressão espaço-tempo" como denominou Harvey (1999). Nesse sentido, originariamente tratou-se de um processo geográfico, entretanto suas implicações econômicas transcenderam a dimensão espacial e contribuíram para reorganizar os processos produtivos e de gestão em escala global.

A principal distinção que pode ser colocada entre a geografia econômica e a geoeconomia, assim como entre a geopolítica e a geografia política, está no foco sobre exercício do poder e sobre as instituições que regulam as condições de produção e reprodução social. $\mathrm{O}$ foco da geografia econômica, desde suas origens enquanto geografia comercial está na explicação da distribuição espacial dos fatos econômicos, considerando os fatores naturais, históricos, sociais e culturais. A geoeconomia procura compreender como o emprego do poder econômico, expresso em um conjunto de manifestações que vão desde o controle sobre a introdução do progresso técnico até definição 
de barreiras à entrada de competidores em mercados crescentemente oligopolizados afeta esta distribuição espacial.

O poder político é exercido através do aparelho de estado e evidentemente não está separado do exercício do poder econômico. Entretanto para que exista o estado é necessária a existência de capacidade tributária, isto é a capacidade de cobrar impostos - em suas mais diversas formas com a finalidade de manter o corpo de funcionários e o controle sobre força militar. Nos modos de produção pré-capitalistas o exercício do poder econômico se fazia através da propriedade sobre os escravos e sobre a terra. Nessas sociedades a transferência do poder se fazia por meio da conquista e da herança e a riqueza possuía muito pouca mobilidade espacial.

No capitalismo, a riqueza monetária assume importância decisiva. Trata-se da separação do excedente agrário, cuja fonte é a explotação da terra e do trabalho, para o excedente econômico, onde o capital ganha autonomia crescente em relação ao território, isto é aumenta a sua mobilidade espacial. Essa autonomia se expressa na sua forma mais clara nas decisões de investimento, isto é na escolha de quando, onde e como investir o capital acumulado. No século XIX, Marx mostrou que era justamente nessa autonomia de decisão, isto é, no que chamava de "anarquia capitalista", que residia o fundamento das crises periódicas do sistema.

Sem entrar profundamente na questão, pois não é o objetivo do presente trabalho, é importante lembrar que na lógica de Marx, seria possível substituir a anarquia de decisões de investimento dos capitalistas pelo que chamava de "socialismo científico", onde o estado cumpriria o papel de capitalista coletivo tomando decisões racionais entre produzir bens de produção ou de consumo. Esta seria uma passagem necessária para o sistema comunista, onde as decisões de investimento seriam tomadas pelo princípio ético de "de cada um de acordo com suas possibilidades e para cada um de acordo com a sua necessidade". O desenvolvimento posterior do sistema capitalista mostrou a falência do cálculo de balanço econômico adotado pelo planejamento centralizado dos países do Leste europeu e o capitalismo modificou substancialmente sua forma de produção para o "just in time", o que significa a possibilidade de fracionar os investimentos em redes produtivas.

A base do poder econômico no capitalismo está justamente na decisão entre consumir ou investir - no sentido macroeconômico; poupar. Os principais economistas do século XX, como Keynes, Kalesky ou Robinson, mostraram que a essência do funcionamento do sistema capitalista está nas chamadas decisões de gasto dos capitalistas e que sua lógica não é determinada por nenhum interesse social ou objetivo moral, mas sim pela concorrência entre eles e pelas expectativas futuras de ganhos, definindo o que se convencionou chamar de "estado geral dos negócios", ou mais modernamente, de "comportamento dos mercados".

A crescente concentração e centralização de capital em grupos econômicos, que formam verdadeiros conglomerados financeiros, característicos da Segunda Revolução Industrial, conferiram maior autonomia decisória - e portanto poder econômico, e maior mobilidade ao capitalismo durante o século XX. Por outro lado, o processo de descolonização e a crescente fragmentação política levaram a emergência de estados-nações que sequer têm capacidade tributária para manter o seus aparelhos de estado, muitas vezes dependentes de transferências internacionais de renda.

O poder econômico dos grandes conglomerados também se manifesta na capacidade de controlar mercados que extrapolam em muito os limites nacionais. No final do século XIX, economias continentais como os EUA criaram leis antitrustes para tentar conter o poder de impor as regras dos mercados de grandes empresas que controlavam desde as minas até a distribuição dos produtos. No final do século XX, com a mundialização financeira, as leis antitrustes começam a ganhar contornos de extra-territorialidade, passando a serem aplicadas como mecanismos de defesa contra monopólios ou quase monopólios que operam foram dos limites nacionais, mas têm o poder de desestabilizar as estruturas de mercado domésticas.

As idéias de poder e de potência estão intimamente associadas à ciência política. Em economia foram de extrema relevância para os clássicos, que a definiam como economia política, mas perderam importância para os neoclássicos que construíram seu edifício conceitual sobre a lógica 
do equilíbrio e da livre concorrência no acesso aos mercados. Nos anos que precederam a Segunda Grande Guerra, os preceitos sobre o livre acesso ao mercado começaram a ser substituídos por noções como concorrência monopólica e oligopólica, que mostravam que as imperfeições desta instituição basilar do capitalismo não eram tão transitórias como acreditam os neoclássicos. Do ponto de vista dos efeitos da concorrência sobre a dinâmica espacial do capitalismo, dois autores se destacam no imediato pós-guerra pela importância de suas construções conceituais e pelos seus impactos sobre o pensamento geográfico: Myrdal e Perroux.

Myrdal foi um economista heterodoxo para o seu tempo e trabalhou sobre questões que vão desde a inserção racial até economia internacional. Seu ponto de vista era institucionalista, conforme manifestou publicamente (MYRDAL; 1978). Quanto à dinâmica espacial, sua contribuição mais importante está no "princípio da causação circular" apresentado em seu clássico Teoria Econômica e Regiões Subdesenvolvidas (MYRDAL; 1960). Segundo esse princípio, a lógica do investimento capitalista -operando segundo as regras do mercado, tende à aglomeração e a concentração nas áreas mais dinâmicas, reforçando as tendências históricas que produziram as desigualdades regionais, o que obrigaria a medidas compensatórias por parte do estado.

Já Perroux, que ficou conhecido pelos pólos de desenvolvimento, construiu uma concepção de espaço econômico como um campo de forças onde atuavam as economias dominantes, vistas como firmas capazes de influenciar o comportamento econômico e espacial do mercado. Perroux se preocupava diretamente com as relações entre poder e economia e, de certa maneira, sua divisão entre espaço econômico e geográfico - que denominava de banal, foi um precursor da separação entre os fluxos (campo de forças) e lugares (PERROUX; 1969).

\section{GEOECONOMIA: REDES E INSTITUIÇÕES}

Geopolítica e geoeconomia não são campos excludentes. Se de um lado, a geopolítica se fundamenta no controle estratégico dos lugares, a geoeconomia atua preferencialmente sobre a logística das redes. É essa articulação que define as relações espaciais de poder entre domínios e fronteiras, que redesenham constantemente os contornos do mapa do mundo atual.

Neste contexto, a principal noção que serviu de base à geografia econômica, isto é, o mercado nacional, tem hoje reduzido poder de explicação sobre o comportamento dinâmico da produção e distribuição de bens, em grande parte devido às condições de integração multilocacional das cadeias produtivas.

Da mesma maneira, a noção de limites, como uma linha divisória entre os territórios e mercados nacionais, devido a fluidez dos circuitos internacionais de bens e capitais, perdeu boa parte de seu poder explicativo, na medida em que os instrumentos clássicos de atuação do Estado-nação perdem seu poder de estabelecer fronteiras, em função do poder que dispõem as firmas transnacionais para delimitar, através de mecanismos econômicos, suas respectivas áreas de influência.

As redes técnicas constituem um capítulo a parte em economia, na medida em que são submetidas a um "quase-monopólio natural" por parte daqueles que detém o seu controle, porque é praticamente impossível a existência de duas ou mais redes de infra-estrutura paralelas disputando o mercado em uma determinada área geoeconômica. As redes de infra-estrutura implicam em elevada escala, integração e indivisibilidade que implicam em custos fixos elevados e manutenção onerosa. Isto levou a progressiva transferência desse monopólio para concessionárias públicas, cuja atividade passou a obedecer a regulamentação dos próprios governos nacionais.

Entretanto, a partir dos anos 90, com a perda de capacidade financeira dos estados e a difusão do receituário do neoliberal, muitos governos utilizaram o expediente da privatização dos serviços públicos como instrumento para reduzir seus déficits fiscais e financeiros e transferir o ônus da manutenção e da expansão das redes de infra-estrutura para o setor privado, através da concessão dos direitos de sua exploração por um determinado período de tempo. A privatização ocorreu em 
praticamente todos os países da América do Sul, sendo particularmente intensa na Argentina, Chile e Bolívia. No Brasil, apesar da privatização de diversas redes, como a ferroviária e de telecomunicações, a presença de empresas estatais ainda é decisiva na geração e distribuição de energia elétrica e no setor de petróleo e gás natural, em grande parte devido à resistência de um amplo arco de interesses políticos e sociais, que incluiu desde setores das forças armadas até movimentos sociais dos trabalhadores.

Desde meados da década de 1990, é possível observar um crescimento da abordagem institucionalista nos trabalhos de Geografia Econômica (SCOTT, 1999; JESSOP, 1995 e 2001; PECK, 2000) que analisam a mudança do papel do Estado como agente econômico para o fortalecimento das funções de regulação, que em uma perspectiva dinâmica que não priorizam uma escala específica, mas ao contrário, consideram as regiões produzidas e reproduzidas pela ação de organizações e instituições. A aplicação desta concepção ao setor energético sul-americano já resultaram em diversos trabalhos, dos quais se destacam Egler, C. A. G. (2006) e Egler, C. A. G. e Pires do Rio, G. A. (2003), onde se procurou mostrar a relevância do marco regulatório, em um contexto institucional e geoeconômico.

Considerando as relações sociais que afetam a territorialidade, do ponto de vista geoeconômico, podemos destacar as relações de propriedade fundiária, mercantis, salariais e financeiras. A propriedade fundiária, isto é, entre os proprietários e os não-proprietários de terra, é uma relação básica na economia capitalista e decisiva na construção das Américas. As vias de desenvolvimento do capitalismo na América do Norte passaram por um processo de reorganização fundiária que não aconteceu plenamente ao sul do Equador, principalmente considerando as duas principais economias do Cone Sul: o Brasil e a Argentina.

Do ponto de vista territorial, a propriedade fundiária regula o acesso ao lugar e, a partir daí, define boa parte da posição das pessoas e dos grupos na estrutura social. A lógica do acesso ao lugar também é um aspecto importante para definir as características básicas do uso da terra. Prado Junior, quando separa as colônias de povoamento das de exploração nas Américas, definiu não apenas o sentido do processo de colonização, mas também a lógica que o é subjacente quanto ao acesso e ao uso dos recursos naturais. Do ponto de vista das escalas geográficas, as relações de propriedade da terra tem o efeito direto nas estruturas produtivas locais, embora seus efeitos indiretos se entendam a espaços mais amplos.

A segunda instância social básica para definir a territorialidade são as relações mercantis, isto é aquelas que se estabelecem entre vendedores e compradores. As relações mercantis estão na base do processo de acumulação primitiva que alicerçam o desenvolvimento do capitalismo. Para que existam vendedores e compradores é necessária certa autonomia em relação à propriedade fundiária e certa independência entre os produtores, de modo a que se desenvolva a divisão social e territorial do trabalho que, segundo a lógica da economia política clássica de Adam Smith e Ricardo, é a alavanca fundamental para a formação do mercado doméstico para o capitalismo. O monopólio e o escravismo colonial foram barreiras difíceis de serem transpostas para a conformação dos mercados americanos e as formas de difusão das relações mercantis foram muito heterogêneas no continente, a tal ponto que até hoje se pode encontrar desde sociedades de consumo de massa até vastas populações que ainda vivem da economia de subsistência com esporádicas trocas de escambo. As relações comerciais tem efeito direto na escala regional, com a formação de regiões mercantis, embora suas articulações estendam-se em escala internacional.

A disseminação das relações salariais, isto é entre os detentores dos meios de produção e os vendedores de força de trabalho estão na base do desenvolvimento de estruturas tipicamente capitalistas de produção e da consolidação de formas monetárias de regulação da vida social. A transformação da riqueza em renda, isto é de estoque em fluxo, é a chave mestra do processo de criação do excedente econômico, que passa a não depender mais do estoque de terras ou de mercadorias, para sua expansão e acumulação ampliada. 
O caráter tardio da difusão das relações assalariadas nas Américas, que só começou a ser efetiva após a Guerra da Secessão nos Estados Unidos (1861-1865) onde se confrontaram dois sistemas de regulação das relações de trabalho, um fundado no assalariamento e outro no escravismo. A importância da guerra não se restringe aos EUA, pois seus efeitos se fizeram sentir em todo o continente americano, inclusive no Brasil, que a partir de 1870 acelerou o processo de imigração e a expansão das relações salariais nas plantações de café. As relações salariais se manifestam diretamente na escala nacional, com a formação dos mercados de força de trabalho e a adoção da moeda nacional como forma de sua regulação.

As relações financeiras, isto é, entre credores e devedores, estão presentes - na sua forma elementar, em todas as relações sociais descritas até agora. Seja na propriedade fundiária, onde o preço da terra é estimado pela renda capitalizada, seja nas relações salariais, na medida em que o trabalho é adiantado em relação ao seu pagamento, seja nas relações mercantis, pois " evidências históricas sugerem que virtualmente todo o 'comércio' desde os tempos mais primitivos era realizado à base de créditos e débitos” (WRAY; 2003: 61).

Entretanto, foi durante o século XX que as relações financeiras assumem relativa proeminência diante das demais relações sociais, configurando aquilo que Hilferding denominou genericamente de Capitalismo Financeiro, como uma forma peculiar de integração entre o capital bancário e o industrial e caracteriza a fase mais avançada do desenvolvimento do capitalismo e têm nos bancos seus principais agentes de disseminação e controle sobre o poder de investimento.

O papel das regiões na integração supranacional

Alguns esclarecimentos preliminares se fazem necessários para apresentar as formas contemporâneas de manifestação da questão regional em uma economia globalizada e financeiramente integrada. Diversos autores, de diferentes orientações conceituais, têm tratado dessas formas transformadas de uma velha questão colocada na essência do desenvolvimento do capitalismo. Tomando, por exemplo, o papel das regiões na estruturação da União Européia, pode-se encontrar posições que duvidam da capacidade das regiões de manter sua autonomia diante do poderio meso-econômico das grandes empresas multinacionais (HOLLAND, 1976 e 1981) e, por outro lado, defensores das vantagens que as novas formas de poder derivadas da autonomia das regiões podem conferir ao sistema financeiro global, reduzindo as barreiras impostas pelo Estado-nação para sua livre circulação (O’BRIEN, 1992 e OHMAE, 1996).

Em trabalhos anteriores (EGLER 1995a, 1995b e 1996), apresentou-se a questão re $\neg$ gional como uma questão de Estado, na medida em que sua resolução passa necessariamente pela composição do bloco no poder e pelas medidas de políticas públicas que afetam a economia nacional e a distribuição territorial da renda. Mais do que isso, mostrou-se que os interesses regionais projetam-se em políticas públicas, cuja forma mais elementar está presente na relação entre capital e província, cuja existência material só é possível a partir de uma deter $\neg$ mi $\neg$ nada política tributária e de alocação do gasto público por parte do Estado no território.

No entanto, experiência atual da União Européia mostra que a questão regional extrapolou os limites do Estado nacional e se apresenta como uma nova forma de representação política supranacional, de alocação comunitária de recursos financeiros e de competição econômica por fundos públicos e privados. Nesse contexto, é importante buscar avançar o debate em torno da dimensão regional do desenvolvimento em um contexto mais amplo, que pode trazer alguns ensinamentos para a realidade vivida no Mercosul.

O instrumental analítico da geografia econômica acerca do desenvolvimento nacional e regional avançou de modo significativo a partir do último quartel do século XX. Dentre as formulações teóricas disponíveis para dissecar o crescimento desigual entre nações e regiões pode-se destacar desde formulações gerais, como é o exemplo de Landes (1998), que procura traçar um abrangente painel histórico do desenvolvimento do capitalismo, partindo das condições geográficas até a consolidação das instituições estáveis e duradouras que garantem as normas e regras para o funcionamento da vida social. 
Geografia e instituições também estão presentes em uma série de estudos promovidos tanto pela chamada nova economia geográfica, como pela geografia econômica de viés institucionalista e evolucionista. Neste trabalho, vamos nos deter principalmente na dimensão espacial das relações que se estabelecem entre distintas formas territoriais elementares, buscando incorporar estas novas concepções, tais como cidade e campo, capital e província, centro e periferia e, por final, entre região e nação, buscando defini-las como categorias que só podem ser compreendidas como relacionais, isto é, que pressupõem a definição em um mesmo campo teórico e conceitual.

A relação espacial capital-província é a forma mais elementar de manifestação da institucionalidade territorial do Estado. Pode-se afirmar que, é através da imposição de uma estrutura de cobrança de tributos sobre as províncias e na centralização da decisão de alocação do gasto público na capital, que o Estado delineia os contornos efetivos do território nacional. Esta é a lógica essencial do mercantilismo que orientou o processo de constituição econômica daquilo que pode ser definido como o Estado moderno.

A relação espacial cidade-campo, por outro lado, é a expressão essencial da institucionalidade territorial do mercado. Desde Adam Smith, que a separação da cidade do campo é base para a divisão social e territorial do trabalho que permite a formação do mercado doméstico. Nesse sentido, o mercado possui também uma nítida expressão territorial

Myrdal (1968) mostra que, em conseqüência da divisão da Europa em blocos políticos polarizados no pós-guerra, as organizações subregionais foram gradativamente ganhando estabilidade e efetividade, ocupando o espaço que as estruturas políticas nacionais estavam impedidas de atuar, em função de suas limitações políticas. Tratava-se de uma forma de 'bonapartismo territorial', onde devido ao vácuo de poder criado por restrições de ordem maior, abriu-se uma brecha para que estruturas políticas territoriais de menores dimensões atuassem e consolidassem suas posições.

\section{CONSIDERAÇÕES FINAIS}

Neste tópico será discutida a adequação de uma proposta de uma regionalização na escala do Mercosul, considerando os objetivos de integração econômica e de redução das disparidades territoriais de renda, bem como buscar uma visão mais adequada das distintas estruturas produtivas, com vistas a permitir comparações entre elas.

As regionalizações disponíveis até o presente momento atendem às demandas nacionais de gestão do território e de correção das disparidades interregionais de renda, porém pouco ou nada atendem a uma política explicita de integração sul-americana. Vários estudos sobre as regiões da Argentina (ROFMAN, 1974 e SILVEIRA, 2003) são importantes marcos preliminares e existem propostas recentes de revisão da regionalização brasileira, como aquela realizada pela equipe do CEDEPLAR (BRASIL, 2008).

A regionalização atual do Brasil, quando comparada com os demais países do MERCOSUL especialmente o Paraguai e o Uruguai, produz grandes assimetrias, tanto no que diz respeito à extensão territorial, como à população e aos principais indicadores econômicos. Com o intuito de reduzir estas assimetrias, expressar as novas tendências territoriais e compatibilizar a estrutura regional no MERCOSUL, elaborou-se a seguinte configuração regional, que procura compatibilizar as dimensões geoeconômicas dos países-membros do Tratado de Assunção. 


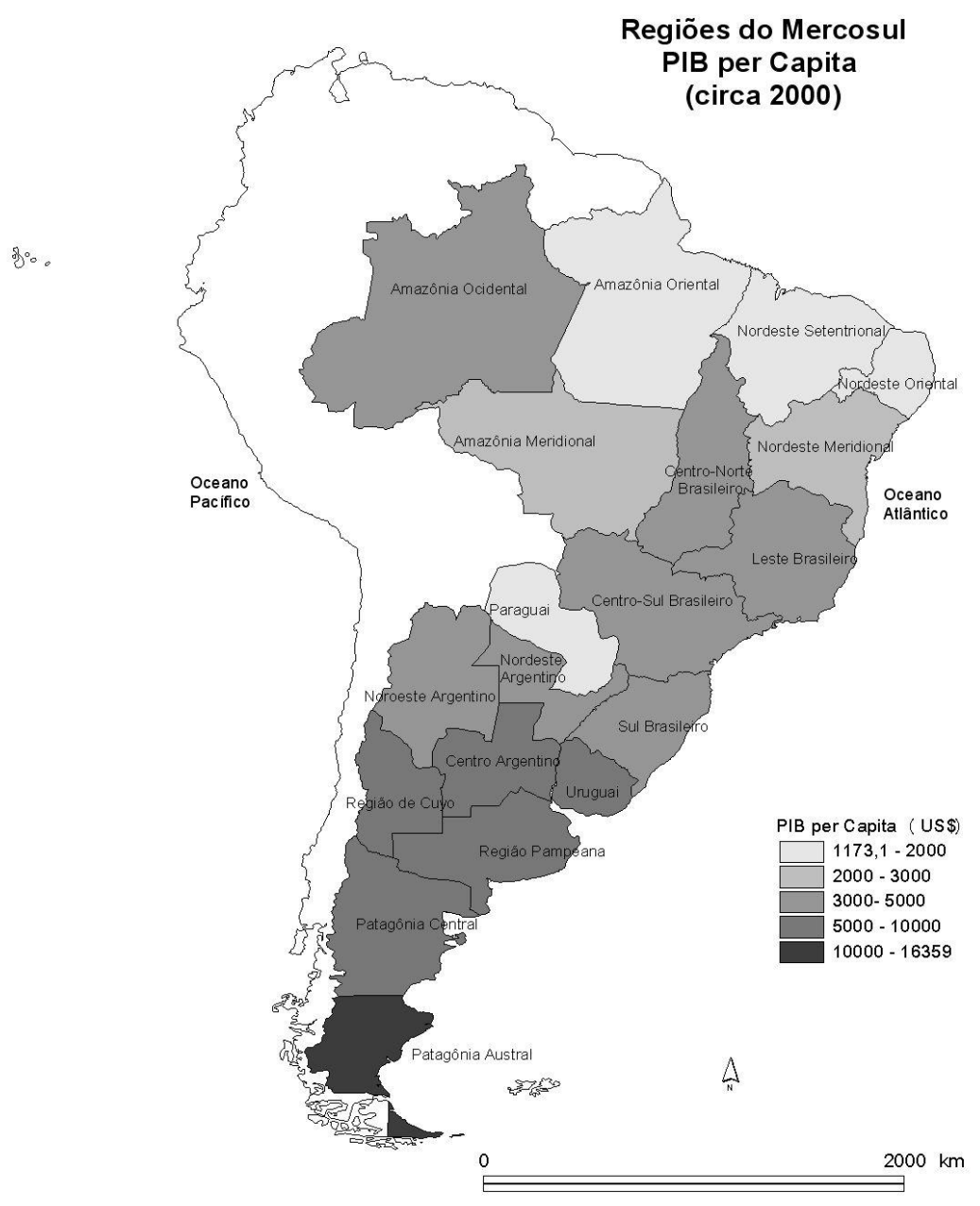

Figura 2 - Regiões do Mercusul PIB per Capita (2000)

A proposta de regionalização apresentada no cartograma é apenas um esboço preliminar, porém mostra que é necessário repensar a própria divisão regional do Brasil, que no passado alimentou a proposta do "Brasil Potência" dos anos 70, porém que hoje tem muito pouco a contribuir para o processo de integração sul-americano.

\section{REFERENCIA BIBLIOGRAFICA}

AMIN, A. An Institutionalist Perspective on Regional Economic Development. Economic Research Group Seminar "Institutions and Governance", London. 1998.

BRASIL. Ministério do Planejamento, Orçamento e Gestão. Estudo da Dimensão Territorial para o Planejamento: Volume III - Regiões de Referência. Brasília, DF: MPOG, 2008. (Disponível em http:// www.planejamento.gov.br/secretarias/upload/ Arquivos/spi/programas_projeto/planejamento_territorial/ plan_ter_Vol3.pdf)

CASTELLS, M. Mudança Econômica e Tecnológica e a Nova Divisão Espacial do Trabalho. Espaço e Debates, v. VI, n. 17, 1986. p. 5-23. 
CUMBERS, A, MACKINNON, D e MCMASTER, R. Institutions, Power and Space: Assessing the limits to institutionalism in Economic Geography. European Urban and Regional Studies 10(4):325-342, 2003. EGLER, Claudio A. G. A questão regional no Brasil. In CHRISTOFOLETTI, A. et al. (ed.). Geografia e meio ambiente. São Paulo: HUCITEC. pp. 218-234, 1995a

EGLER, Claudio A. G. Questão Regional e Gestão do Território no Brasil. In CASTRO, I. . E. et al. (ed.). Geografia : conceitos e temas. Rio de Janeiro: Bertrand Brasil. pp. 207-238, 1995b

EGLER, Claudio A. G. Crise e dinâmica das estruturas produtivas regionais no Brasil. In CASTRO, I. . E. et al. (ed.). Brasil. Questões Atuais da Reorganização do Território. Rio de Janeiro: Bertrand Brasil. p. 185-220, 1996

EGLER, Claudio A. G. Mercosul: um território em construção? Ciência e Cultura (58) 1, 24-28, 2006

EGLER, Cláudio.A.G e PIRES DO RIO, Gisela A. O novo mapa institucional: o papel das agências reguladoras na gestão do território. Anais do V Encontro da Associação Nacional de Pós-Graduação de Pesquisa em Geografia. Florianópolis, 3 a 5 de setembro, 2003

EGLER, Cláudio.A.G e PIRES DO RIO, Gisela A. Ambiente Institucional e Redes Globais: o exemplo da Petrobrás. Anais do IV Congresso Europeu de Latinoamericanistas, Bratislava; Vol. 1; 65-75 p, 2004

FIORI, J. L. O sistema interestatal capitalista no início do século XXI. In: Jose Luís Fiori; C. A. de Medeiros; Franklin Serrano (Orgs.); O Mito do Colapso do Poder Americano. p. 11-70. Rio de Janeiro: Record, 2008. GUIMARÃES, Fábio M. S. Divisão Regional do Brasil. Rev. Bras. Geografia (3) 2, 318-373, 1941.

HARVEY, D. Theorizing the Transition...Flexible Accumulation - Solid Transformation or Temporary Fix? In: J. Bryson; N. Henry; D. Keeble; R. Martin (Orgs.); The Economic Geography Reader. p.46-51. Chichester, UK: John Wiley \& Sons, 1999.

HOLLAND, S. The regional problem. London: MacMillan Press, 1976.

HOLLAND, S. El Mercado Incomun, Madrid: H. Blume Ediciones, 1981. http://www.integracao.gov.br/ docs/desenvolvimentoregional/textos_basicos_pnot.zip, .

JESSOP, B. The regulation approach, governance and post-fordism: alternative perspectives on economic and political change? Economy and Society 24, 307-333, 1995.

JESSOP, B. Institutional re(turns) and the strategic-relational approach. Environment and Planning A 33 (7): 1213-1235, 2001.

LANDES, David S. A Riqueza e a Pobreza das Nações. Rio de Janeiro: Campus, 1998.

LÜTGENS, R. Los fundamentos geográficos y los problemas de la vida económica., Vol 1, Barcelona: Omega, 1954.

MYRDAL, G. Teoria econômica e regiões subdesenvolvidas. Rio de Janeiro: INEP, 1960.

MYRDAL, G. Twenty years of the United Nations Economic Commission for Europe. International Organization. Summer 1968, n 3; Vol XXII, p. 617-628., 1968

MYRDAL, G. Institutional Economics. Journal of Economics Issues, v. 12, n. 4, p. 771-783, 1978.

NORTH, Douglass C. Instituciones, cambio institucional y desempeño económico. México, DF: Fondo de Cultura Econômica, 2001.

O'BRIEN, R. Global financial integration: the end of geography. London: Royal Institute of International Affairs, 1992.

OHMAE, K. O fim do Estado-nação: a ascensão das economias regionais. Rio de Janeiro: Campus, 1996. PANAIA, M. Los actores de la transformación territorial con las nuevas reglas del juego de la integración en el Mercosur. In LAURELLI, E. (ed.). Nuevas territorialidades: desafíos para América Latina frente al siglo XXI. La Plata, Ar: Ediciones Al Margen. pp. 221-252, 2004.

PERROUX, F. L'effet de domination et les relations économiques. Économie appliquée (40) 2, 271-290 p., 1949

PERROUX, F. L' Economie du XXeme siècle. Paris: PUF, 1969.

POCHMANN, M. Geoeconomia do Emprego no Nordeste Brasileiro. In Macambira, J. e Santos, S.M. (ed.). Brasil e Nordeste: Ocupação, Desemprego e Desigualdade. Fortaleza, CE: BNB. p. 65-82., 2007 
RENNER, G. T. Human Geography in the Air Age. New York: Macmillan, 1942.

ROFMAN, A. Desigualdades regionales y concentracion económica : el caso argentino. Buenos Aires: SIAP, 1974.

COUTO E SILVA, G. Geopolítica do Brasil. Rio de Janeiro: José Olympio, 1967

SCOTT, A. J. La Nouvelle Géoéconomie des Régions. In: P. Lorot (Org.); Introduction à la Géoéconomie. p.67-72. Paris: Economica, 1999.

SILVEIRA, Maria L.. Argentina: território e globalização. São Paulo: Brasiliense, 2003.

SILVEIRA, Maria L. (ed.) Continente em chamas. Globalização e território na América Latina. Rio de Janeiro: Civilização Brasileira, 2005.

SIROËN, J.-M. La régionalisation de l'économie mondiale. Paris: La Découverte, 2004.

STORPER, M. The Regional World. Territorial Development in a Global Economy. New York: The Gilford Press, 1997.

TAVARES, M. C. Império, Território e Dinheiro. In: J. L. Fiori (Org.); Estado e Moedas no desenvolvimento das nações. p.449-489. Petropólis, RJ: Vozes, 1999.

TAYLOR, P. J. World City Network: A Global Urban Analysis. London: Routledge (UK), 2003.

WRAY, L. R. Trabalho e moeda hoje: a chave para o pleno emprego e a estabilidade dos preços. Editora da UFRJ/Contraponto, 2003. 